\title{
A FE Model for TRM Reinforced Masonry Walls with Interface Effects
}

\section{GULINELLI Pietro 1,2,3,a*, APRILE Alessandra ${ }^{2, b}$, RIZZONI Raffaella ${ }^{2, c}$, GRUNEVALD Yves-Henri ${ }^{1,3, \mathrm{~d}}$, LEBON Frédéric ${ }^{1, \mathrm{e}}$, LOVISETTO Roberto ${ }^{4, \mathrm{f}}$, TRALLI Sergio ${ }^{4,9}$}

\author{
'LMA, CNRS, 4 Impasse Nikola Tesla, 13013 Marseille, France \\ ${ }^{2} \mathrm{DE}$, University of Ferrara, Via Saragat 1, 44122 Ferrara, Italy \\ ${ }^{3}$ Composites Expertise \& Solutions, 131 TRAV Penne aux Camoins, BT4 ID Dom Actiparc 1, \\ 13821 La Penne-sur-Huveaune, France \\ ${ }^{4}$ LiFE S.r.I. , via Ascari, 6, 44019 Gualdo di Voghiera, Ferrara, Italy \\ apietro.gulinelli@unife.it, balessandra.aprile@unife.it, craffaella.rizzoni@unife.it, \\ dyh.grunevald@composites-expertise-solutions.com, Ilebon@lma.cnrs-mrs, \\ frobertolovisetto@lifelab.it, gsergiotralli@lifelab.it
}

Keywords: reinforced masonry; diagonal compression tests; anchors; finite elements; interface models; cohesive elements.

\begin{abstract}
We report on experimental and numerical investigations of textile reinforced mortar (TRM) strengthening systems, an innovative solution for reinforcing historical masonry structures. The experimental campaign presented in this paper is original and concerns two commercial TRM applications to single-leaf clay masonry panels. The proposed FE modelling is based on a multiscale approach with the possibility of simulating bed joints sliding and TRM-reinforcement debonding. This last phenomenon is frequently reported in the experimental literature and it has been observed also in our experimental tests. The numerical model is applied to study the behaviour of TRM reinforced masonry panels under diagonal compression tests.
\end{abstract}

\section{Introduction}

Conventional seismic retrofitting techniques for historical masonry structures are usually based on steel reinforced concrete jacketing. New developments of materials, methods and techniques for structural strengthening have promoted the use of composite materials in the form of fibre reinforced polymer (FRP) materials, and, more recently, of textile reinforced mortar (TRM). TRMs, also known as fibre reinforced cementitious matrix (FRCM) [1], are innovative composites constituted of high-strength fibres (basalt, glass, steel) in the form of grids embedded into inorganic matrices, such as natural mortars or cements. Over the last decade, many experimental studies have been carried out to investigate the effectiveness of TRM composites in different load configurations, see for example [2-10]. Different design approaches are currently available for quantifying the strength of masonry walls externally reinforced by composite materials $[2,8,11]$. Finite element modelling of TRM strengthened masonry, although a complex task, is a useful approach for understanding the role of material parameters on the behaviour of strengthened structures. In the literature, a limited number of numerical models has been proposed to investigate the structural behaviour of TRM strengthened masonry [5, 11-16]. In these numerical models, perfect contact is assumed between the masonry substrate and the external reinforcement. Moreover, masonry is treated as a continuum equivalent material. In the present paper, a different multiscale strategy for the failure analysis of TRM-reinforced masonry is proposed, based on the introduction of cohesive laws between mortar joints and masonry bricks and between reinforcing composite layers and masonry panel, employing suitable cohesive interface elements. The reinforcement layers are modelled as composite laminates with equivalent material properties and discretized using two-dimensional shell elements. The result is an original numerical model, implemented in Abaqus and successfully applied to simulate the behaviour of masonry panels reinforced with commercial TRM systems and subjected to diagonal compression tests. 


\section{Experimental Campaign}

The experimental tests concerned 7 single-leaf masonry panels of global dimensions $1030 \mathrm{x}$ $1000 \times 120 \mathrm{~mm}^{3}$, built with clay bricks (CB) of average dimensions $250 \times 120 \times 55 \mathrm{~mm}^{3}$ arranged in a 14-rows layout. Bed and head joints of thickness $17 \mathrm{~mm}$ and $10 \mathrm{~mm}$ respectively were realized with a low quality lime-based mortar (LM), composed by sand (75\%), lime $(21 \%)$ and cement (4\%). Specimens were built and cured outdoor and were strengthened after their curing period. The experimental campaign was entirely developed at LiFE S.r.l. Two commercial strengthening solutions were applied with double-sided configuration to 6 of the 7 masonry panels. The first commercial TRM system, herein after denoted GTRM, exploits preformed grids (GG) and anchors (GA) of GFRP (Glass Fiber Reinforced Polymer) embedded in natural hydraulic lime mortar matrix (GM) and was applied to 3 specimens. The second TRM system, denoted BTRM, exploits stainless steel and basalt fibre grids (BG) and helical stainless steel anchors (BA) embedded in natural lime mortar matrix added with mineral binder (BM) and was applied to 3 specimens The reinforcements geometry, materials quality and application methods were set according to manufacturer instructions (Table 1). Finally, a single masonry panel left unstrengthened (URM) was tested as control specimen.

Table 1. Specimens' strengthening configurations

\begin{tabular}{|c|c|c|c|c|}
\hline $\begin{array}{l}\text { Specimen } \\
\text { ID }\end{array}$ & $\begin{array}{c}\text { Specimen } \\
\#\end{array}$ & Matrix & Grid & Anchors \\
\hline URM & 1 & --- & --- & --- \\
\hline GTRM & $1-3$ & $\begin{array}{l}\text { Hydraulic lime mortar } \\
\text { sprayed in a single } \\
\text { layer of thickness } \\
30 \mathrm{~mm} \text { per side }\end{array}$ & $\begin{array}{l}\text { Preformed GFRP grid } \\
\text { of mean thickness } \\
3 \mathrm{~mm} \text { and spacing } \\
33 \times 33 \mathrm{~mm}^{2} \text { per side }\end{array}$ & $\begin{array}{l}\text { Coupled L-shaped } \\
\text { preformed GFRP } \\
\text { anchors of section } \\
70 \mathrm{~mm}^{2} \text { and length } \\
100 \mathrm{~mm} \text { each }\end{array}$ \\
\hline BTRM & $1-3$ & $\begin{array}{l}\text { Mineral binder-added } \\
\text { lime mortar sprayed in } \\
\text { two layers of total } \\
\text { thickness } 10 \text { mm per } \\
\text { side }\end{array}$ & $\begin{array}{l}\text { Balanced basalt- } \\
\text { stainless steel AISI } 304 \\
\text { grid of mean thickness } \\
0,064 \mathrm{~mm} \text { and spacing } \\
8 \times 8 \mathrm{~mm}^{2} \text { per side }\end{array}$ & $\begin{array}{c}\text { Helical stainless } \\
\text { steel AISI } 316 \\
\text { anchors of section } \\
14,5 \mathrm{~mm}^{2} \text { and length } \\
200 \mathrm{~mm}\end{array}$ \\
\hline
\end{tabular}

Experimental tests for the mechanical characterization of materials were carried out after a curing period of 28 days. Although many innovative testing methods have been proposed in the literature $[17,18]$ for masonry components, the standard approach was selected in this work. Compression tests were performed on clay brick cubes for deriving the average cubic compressive strength, $f_{c}$, according to UNI EN 772-1 standard [19]. Three-point bending tests were carried out on prisms of joint's mortar and matrices of the applied strengthening systems in order to derive the average flexural strength, $f_{t}$, according to UNI EN 1015-11 standard [20]. Finally, a uniaxial compression test was performed on a single small size wall specimen to estimate the elastic modulus, E, and Poisson coefficient, $v$, of bricks and bed-joints mortar, according to EN 1052-1 standard [21]. The main results are summarized in Table 2 in terms of mean values and coefficient of variation $(\mathrm{CoV})$. The main mechanical properties of strengthening grids and anchors as provided by the manufacturer are reported in Table 3 . In order to qualify the shear strength, $f_{0}$, of the mortar-brick interfaces, some triplets were realized and tested, according to UNI EN 1052-3 standard [22]. The main results are summarized in Table 4 in terms of mean values and coefficient of variation $(\mathrm{CoV})$.

Table 2. Experimental mechanical properties of materials

\begin{tabular}{cccccccc} 
Material type & Specimen \# & $\mathrm{f}_{\mathrm{t}}[\mathrm{MPa}]$ & $\mathrm{CoV}[\%]$ & $\mathrm{f}_{\mathrm{c}}[\mathrm{MPa}]$ & $\mathrm{CoV}[\%]$ & $\mathrm{E}[\mathrm{MPa}]$ & $v$ \\
\hline $\mathrm{CB}$ & 20 & --- & --- & 19,37 & 12 & 20.176 & 0.23 \\
$\mathrm{LM}$ & $18-36$ & 0,84 & 25 & 4,64 & 15 & 2.499 & --- \\
$\mathrm{GM}$ & $3-6$ & 1,14 & 10 & 4,58 & 5 & --- & --- \\
BM & $3-6$ & 2,05 & 17 & 8,16 & 3 & --- & ---
\end{tabular}


Table 3. Grids and anchors geometrical and mechanical properties declared by the manufacturer

\begin{tabular}{cccc} 
Material ID & Tensile Strength [MPa] & Elastic Modulus [GPa] & Ultimate Strain [\%] \\
\hline GG & $\geq 350$ & $\geq 27$ & $\geq 1,5$ \\
BG & $\geq 1.700$ & $\geq 70$ & $\geq 1,9$ \\
GA & $\geq 440$ & $\geq 26$ & $\geq 1,7$ \\
BA & $\geq 700(\varepsilon=0,2 \%)$ & $\geq 150$ & $\geq 3,0$
\end{tabular}

Table 4. Bond strength of mortar-brick and matrix-brick interfaces

\begin{tabular}{cccc} 
Interface type & Specimen \# & $\mathrm{f}_{\mathrm{v} 0}[\mathrm{MPa}]$ & $\mathrm{CoV}[\%]$ \\
\hline LM-CB & 8 & 0,29 & 23 \\
GM-CB & 3 & 0,36 & 36 \\
BM-CB & 3 & 0,37 & 68
\end{tabular}

The system BM-CB in Table 4 presents a high value of CoV. A similar values dispersion has been reported in [23]. Nevertheless, all the three triplet types exhibited the same failure mode, i.e. a debonding at the interface between brick and mortar. Experimental in-plane diagonal compression tests were carried out on URM, GTRM and BTRM, according to ASTM E 519 standard [24]. The diagonal compression load was applied to the upper and lower corners of the specimen by using two steel shoes, connected to the masonry panels with a thin layer of shrinkage free mortar to avoid local brittle failures at the interface. The upper steel shoe was connected to a servo hydraulic jack operated by an electrical pump to apply the diagonal compression load. The specimens were tested under displacement control with $0.08 \mathrm{~mm} / \mathrm{s}$ rate. Four linear variable displacement transducers (LVDT) were installed along the two diagonals of both sides of the specimens to monitor the in-plane deformations along principal directions over a gauge length of $500 \mathrm{~mm}$. The behaviour of specimens under in-plane diagonal compression was analysed in terms of load-strain relationship and failure mode. A vertical peak load of $70 \mathrm{kN}$ with vertical deformation of $167 \mu \mathrm{m} / \mathrm{m}$ was reached by URM. Average vertical peak loads of $149 \mathrm{kN}$ and $170 \mathrm{kN}$ were reached by GTRM and BTRM, respectively. The obtained results highlight a meaningful load carrying capacity increase of both GTRM (about 2 times) and BTRM (about 2 times and a half) when compared to URM. Regarding deformation capacity, a meaningful increase can be noticed for GTRM $(+80 \%)$ but information are lacking for BTRM. The URM specimen exhibited a brittle behaviour under testing. The failure mode was due to abrupt bond sliding at the upper $5^{\text {th }}$-row joint, immediately after the peak force (Fig. 1a). BTRM specimens exhibited diagonal failure modes due to traction in horizontal direction (Fig. 1b); failure cracks involved both the bricks and reinforcement matrix, proving a very good efficacy of the strengthening system. Finally, GTRM specimens exhibited debonding of the reinforcement matrix from the wall surface and consequent bond sliding of wall bed-joints immediately after the peak force (Fig. 1c), although initial diagonal crack patterns developed during the tests (Fig. 1d). Even if the loading capacity increase of both the strengthening configurations is appreciable, the failure mode exhibited by BTRM is more efficient since it allows exploiting the overall structural capacity of the original walls.
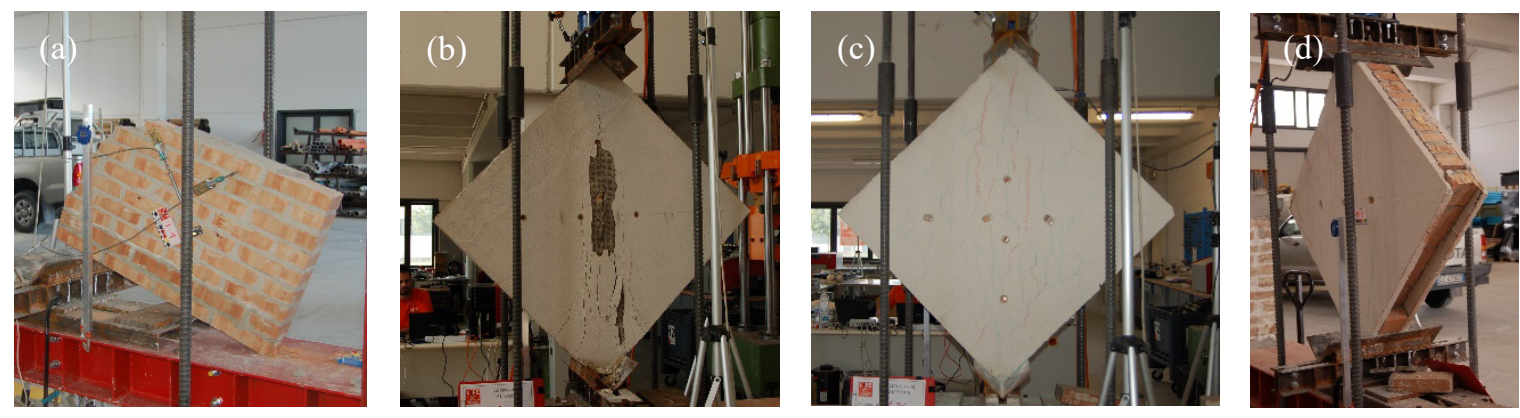

Fig. 1. Typical failure mode of URM (a), BTRM (b), GTRM (c) and GTRM debonding detail (d) 


\section{Numerical Model}

The proposed FE model was implemented in Abaqus through a simplified micro-model approach $[25,26]$. For the sake of brevity, only URM and GTRM numerical models and results are presented herein.

Continuum three-dimensional elements (C3D8) model the masonry wall units, assuming a homogenous, isotropic and infinitely elastic material with brick's elastic properties (Table 2). The GTRM reinforcing layer is modelled as a composite laminate with equivalent elastic stiffness. It is discretized through two-dimensional shell elements (S4), located on $r p$ plan and with normal $r n$ (Fig. 2a). The stacking, shown in Fig. 2a, is assumed according to Table 1. Laminate materials are supposed homogenous and infinitely elastic.

(a)

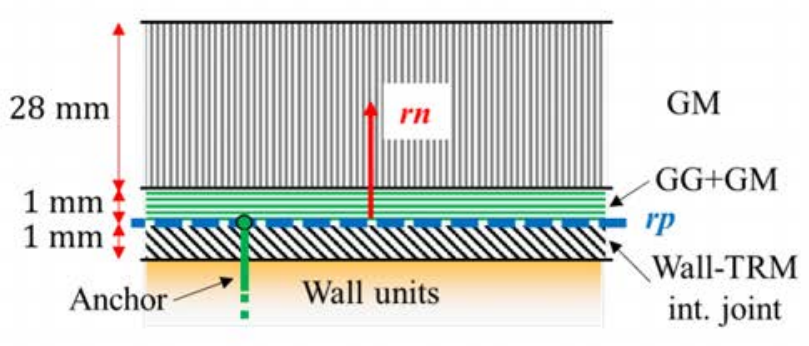

(b)

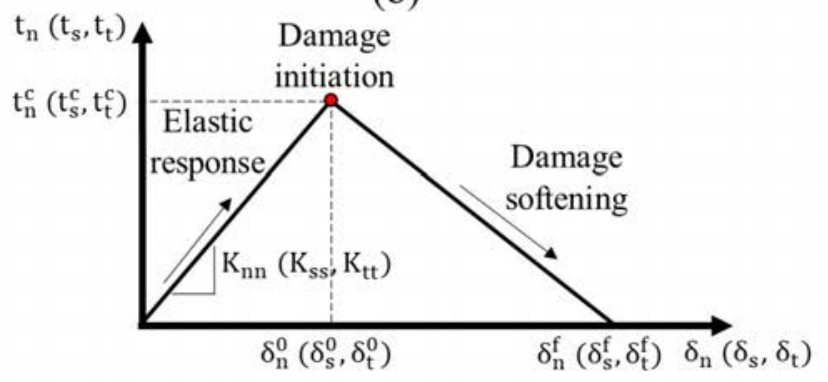

Fig. 2. (a) TRM laminate and Wall-TRM interface, (b) interface joint traction-separation response

The matrix GM is isotropic. The grid/matrix ply (GG+GM, Fig. 2a) is modelled as an orthotropic material with two equivalent principal directions, parallel to grid fibres directions. Treating the ply $\mathrm{GG}+\mathrm{GM}$ as a bidirectional symmetric composite laminate $\left[0^{\circ}, 90^{\circ}, 90^{\circ}, 0^{\circ}\right]$, its homogenized material properties in the plan $r p$ are obtained through rule of mixtures and composite laminate theory [27].

Table 5 reports GTRM laminate properties of each ply, where $V_{f}$ indicates the fibre volume ratio. Out of $r p$ plan, the elastic properties are supposed as the same as GM.

Table 5. GTRM laminate properties

\begin{tabular}{cccccc} 
Ply & $\mathrm{V}_{\mathrm{f}}$ & $\rho\left[\mathrm{kg} / \mathrm{m}^{3}\right]$ & $\mathrm{E}_{\mathrm{rp}}[\mathrm{MPa}]$ & $v_{\mathrm{rp}}$ & $\mathrm{Grp}[\mathrm{MPa}]$ \\
\hline $\mathrm{GM}$ & 0 & 1400 & 2500 & 0.15 & 1087 \\
$\mathrm{GG}+\mathrm{GM}$ & 0.38 & 1862 & 8464 & 0.12 & 2072
\end{tabular}

Unit-Unit and wall-TRM interface joints (Fig. 2a) consist of $1 \mathrm{~mm}$ thick three-dimensional cohesive elements (COH3D8), in which all damage is supposed to concentrate. The constitutive model of these cohesive elements is based on a traction-separation $(\mathbf{t}-\boldsymbol{\delta})$ behaviour, where $\mathbf{t}$ is the traction vector and $\boldsymbol{\delta}$ the relative displacement vector. Such interface behaviour is characterized by an initial linear elastic response and a subsequent damage softening $[25,26]$, as shown in Fig. 2b, in which the subscripts $\mathrm{s}$, $\mathrm{t}$ indicate in-plane components and $\mathrm{n}$ the out-of-plane component. Superscripts $\mathrm{c}, 0$, indicate damage initiation and $\mathrm{f}$ indicates failure. This cohesive model allows to represent two failure modes of the interface joints: tensile cracking and shear sliding. Assuming an uncoupled isotropic $\mathbf{t}-\boldsymbol{\delta}$ behaviour with isotropic response, stiffness components $\left(\mathrm{K}_{\mathrm{nn}}, \mathrm{K}_{\mathrm{ss}}, \mathrm{K}_{\mathrm{tt}}\right)$ can be calculated as function of mortar elastic constants and mortar thickness $h_{m}$ [28]. Table 6 reports the stiffness components of the different joints. For bed and head joints $h_{m}$ is the joint real thickness, and for the wall-TRM interface $h_{m}$ is assumed equal to cohesive element thickness $(1 \mathrm{~mm})$. 
Table 6. Reduced elastic and shear stiffnesses of interface joints

\begin{tabular}{ccccc} 
Joint & Mortar & $\mathrm{h}_{\mathrm{m}}[\mathrm{mm}]$ & $\mathrm{K}_{\mathrm{nn}}\left[\mathrm{N} / \mathrm{mm}^{3}\right]$ & $\mathrm{K}_{\mathrm{ss}}\left(\mathrm{K}_{\mathrm{tt}}\right)\left[\mathrm{N} / \mathrm{mm}^{3}\right]$ \\
\hline Bed joint, bare wall & LM & 17 & 149 & 61 \\
$\begin{array}{c}\text { Head joint, bare } \\
\text { wall } \\
\text { Wall-TRM }\end{array}$ & LM & 10 & 264 & 108 \\
& GM & 1 & 2640 & 1087
\end{tabular}

The post-peak phase describes damage propagation in the cohesive joints. Damage initiates when one of the three traction components, $t_{n}, t_{s}$ and $t_{t}$, locally reaches its critical value, $t_{n}^{c}, t_{s}^{c}, t_{t}^{c}$ respectively (MAXS criterion, Abaqus, [29]). Critical shear stresses $\left(t_{s}^{c}\right.$ and $\left.t_{t}^{c}\right)$ generally depend on normal stress $t_{n}$ according to Mohr-Coulomb failure. The dependency of $t_{s}^{c}$ and $t_{t}^{c}$ on $t_{n}$ was implemented in a user subroutine USDFLD. In the post-peak phase, the stiffness degrades due to damage propagation. The scalar damage variable $\mathrm{D}$ increases from 0 (damage initiation) to 1 (joint completely damaged) during damage softening (Fig. 2b). D depends on the effective separation $\delta_{\text {eff }}$, as reported in [26, 29, 30]. In the current study, a simple linear softening of the effective separation $\delta_{\text {eff }}$ was assumed as damage response, since the attention is focused on the elastic response before damage initiation.

Finally, one-dimensional elements simulate anchors which are used in the analysed reinforcement techniques. Three different models for anchors simulation were studied: truss (T3D2) without interaction with bare wall, free-beam (B31) without interaction with bare wall, and constrained-beam (B31) with displacement compatibility between anchor and masonry wall nodes. In all cases, anchors share a node with the reinforcement layer in the plan $r p$ (Fig. 2a), and their material is assumed isotropic, homogenous and infinitely elastic.

\section{Discussion}

Fig. 3a shows the realized numerical model, characterized by symmetry conditions with respect to the plan YZ. FE simulations were conducted in dynamic regime (implicit integration scheme) to better handle the non-linear constitutive response of the cohesive elements (Fig. 2a, Fig. 3a), which constitute the interface joints. Moreover, upper boundary vertical displacements (Fig. 3a) were imposed in quasi-static conditions in order to reproduce experimental tests, performed with a low load application rate $(0.08 \mathrm{~mm} / \mathrm{s})$. Mesh sensitivity analysis suggested a mesh average size of $30 \mathrm{~mm}$. Fig. 3a shows anchors locations (round ticks), according to manufacturer specifications, and measurement nodes between which numerical vertical strains were estimated (squared ticks). Their positions were chosen to compare numerical vertical strains with experimental ones. Fig. $3 b$ reports the macroscopic force-displacement response. GTRM axial stiffness is generally higher than URM stiffness. The proposed numerical micro-modelling of brick units-mortar and TRM-wall interfaces allows to simulate the experimental crack pattern: bed joint sliding occurs in the displacement range $[240 \div 280 \mu \mathrm{m}]$ for both URM and GTRM while TRM debonding and ultimate failure take place in the range $[580 \div 714 \mu \mathrm{m}]$ for GTRM. A comparison between numerical and average experimental load and deformation peak values is reported in Table 7. Numerical previsions slightly overestimate average experimental peak loads with an error less than $10 \%$, but a lower accuracy is noticed for average experimental peak deformations. 
(a)

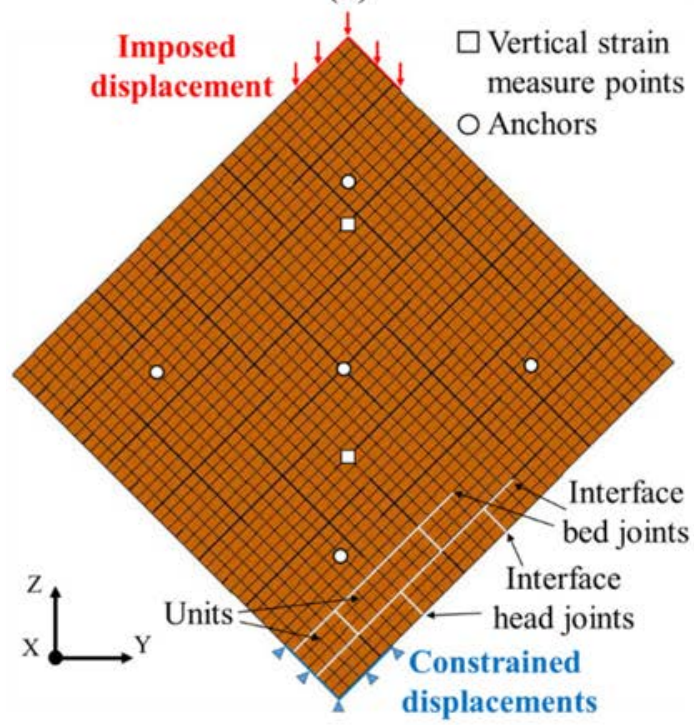

(b)

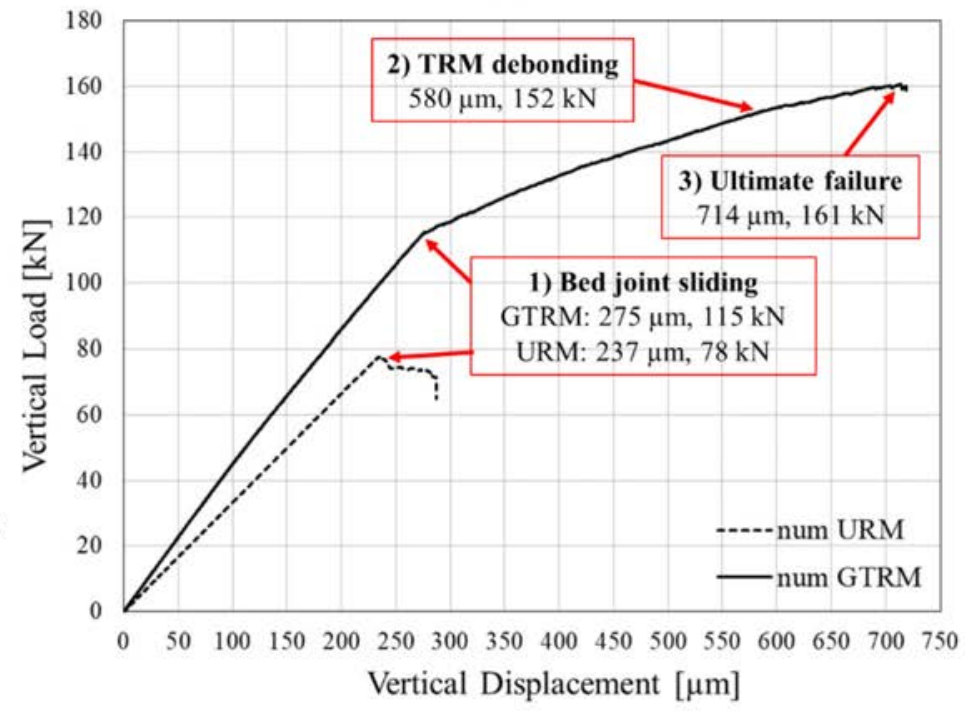

Fig. 3. Numerical model lay-out (a) and numerical load vs displacement curves of GTRM and URM

Table 7. Numerical and experimental values comparison

\begin{tabular}{ccccccc} 
Specimen & $\mathrm{P}_{\mathrm{pk} \text {,num }}[\mathrm{kN}]$ & $\mathrm{P}_{\mathrm{pk} \text {,exp,av }}[\mathrm{kN}]$ & $\Delta \mathrm{P}_{\mathrm{p}}[\%]$ & $\varepsilon_{\mathrm{pk}, \mathrm{num}}[\mu \mathrm{m} / \mathrm{m}]$ & $\varepsilon_{\mathrm{pk} \text {,exp,av }}[\mu \mathrm{m} / \mathrm{m}]$ & $\Delta \varepsilon_{\mathrm{pk}}[\%]$ \\
\hline URM & 78 & 70 & $+10 \%$ & 139 & 166 & $-16 \%$ \\
GTRM & 161 & 149 & $+7 \%$ & 545 & 299 & $+82 \%$
\end{tabular}

Finally, these simulations highlighted that the presence of the anchors does not affect the macroscopic force-displacement response for the three studied anchors' models (truss, free-beam and constrained-beam).

\section{Summary}

In this work, the behaviour of masonry panels strengthened with TRM technique is studied with both experimental and numerical investigations. The performed experimental campaign shows the great potential of this strengthening technique for structural rehabilitation of historical masonry buildings located in earthquake-prone areas. The proposed FE simulations, based on a multiscale approach, show a good prevision capacity of experimental results on URM and GTRM masonry in terms of stiffness, peak load and experimental crack pattern (bed joint sliding and TRM debonding). Therefore, it can be used to explore optimal design options in the future. FE model and numerical results for BTRM will be discussed in future works.

\section{Acknowledgments}

The authors want to thank LiFE S.r.l and Mucchi Lab, Italy, for the support offered to experimental tests. The authors also thank Composites Expertise \& Solutions, LMA-CNRS Marseille, University of Aix-Marseille, France, and University of Ferrara, Italy, for the support offered to numerical analyses. 


\section{References}

[1] DPCSLP n. 1, 08.01.2019, Linea guida per la idendificazione, la qualificazione ed il controllo di accettazione di compositi fibrorinforzati a matrice inorganica (FRCM) da utilizzarsi per il consolidamento strutturale di costruzioni esistenti.

[2] C. Faella, E. Martinelli, E. Nigro, S. Paciello, Shear capacity of masonry walls externally strengthened by a cement-based composite material: An experimental campaign, Constr. Build. Mater. 24 (2010) 84-93.

[3] C. Papanicolaou, T. Triantafillou, M. Lekka, Externally bonded grids as strengthening and seismic retrofitting materials of masonry panels, Constr. Build. Mater. 25 (2011) 504-514.

[4] F. Parisi, I. Iovinella, A. Balsamo, N. Augenti, A. Prota, In-plane behaviour of tuff masonry strengthened with inorganic matrix-grid composites, Compos. Part B-Eng. 45 (2013) 1657-1666.

[5] M. Corradi, A. Borri, G. Castori, R. Sisti, Shear strengthening of wall panels through jacketing with cement mortar reinforced by GFRP grids, Compos. Part B-Eng. 64 (2014) 33-42.

[6] N. Ismail, J. M. Ingham, In-plane and out-of-plane testing of unreinforced masonry walls strengthened using polymer textile reinforced mortar, Eng. Struct. 118 (2016) 167-177.

[7] Y. Yardim, O. Lalaj, Shear strengthening of unreinforced masonry wall with different fiber reinforced mortar jacketing, Constr. Build. Mater. 102 (2016) 149-154.

[8] L. A. S. Kouris, T. C. Triantafillou, Design Methods for Strengthening Masonry Buildings Using Textile-Reinforced Mortar, Journal of Composites for Construction 23 (2018), 04018070.

[9] M. Shabdin, M. Zargaran, Nader K.A. Attari, Experimental diagonal tension (shear) test of UnReinforced Masonry (URM) walls strengthened with textile reinforced mortar (TRM), Constr. Build. Mater. 164 (2018) 704-715.

[10] X. Wang, C. C. Lam, V. P. Iu, Experimental investigation of in-plane shear behaviour of grey clay brick masonry panels strengthened with SRG, Eng. Struct. 162 (2018) 84-96.

[11] M. Basili, G. Marcari, F. Vestroni, Nonlinear analysis of masonry panels strengthened with textile reinforced mortar, Eng. Struct. 113 (2016) 245-258.

[12] Garofano, F. Ceroni, M. Pecce, Modelling of the in-plane behaviour of masonry walls strengthened with polymeric grids embedded in cementitious mortar layers, Compos. Part BEng. 85 (2016) 243-258.

[13] L. Bui, N. Reboul, A. Si Larbi, E. Ferrier, Mechanical in-plane behaviour of masonry walls reinforced by composite materials: Experimental and analytical approaches, J. Compos. Mater. 51 (2017) 4231-4249.

[14] C.B. De Carvalho Bello, A. Cecchi, E. Meroi, D.V. Oliveira, Experimental and numerical investigations on the behaviour of masonry walls reinforced with an innovative sisal FRCM system, Key Eng. Mater. 747 (2017) 190-195.

[15] G. Mininno, B. Ghiassi, D. V. Oliveira, Modeling of in-plane and out-of-plane performance of TRM-strengthened masonry walls, Key Eng. Mater. 747 (2017) 60-68.

[16] X. Wang, Bahman Ghiassi, Daniel V. Oliveira, C.C. Lam, Modelling the nonlinear behaviour of masonry walls strengthened with textile reinforced mortars, Eng. Struct. 134 (2017) 11-24.

[17] L. Pelà, E. Canella, A. Aprile, P. Roca Fabregat. Compression test of masonry core samples extracted from existing brickwork. Constr. Build. Mater., 119 (2016) 230-240.

[18] L. Pelà, P. Roca, A. Aprile. Combined in-situ and laboratory minor destructive testing of historical mortars. Int. J. Archit. Herit., 12-3 (2018), 334-349. 
[19] UNI EN 772-1:2015. Methods of test for masonry units - Part 1: Determination of compressive strength.

[20] UNI EN 1015-11:2007. Methods of test for mortar for masonry - Part 11: Determination of flexural and compressive strength of hardened mortar.

[21] EN 1052-1:2001. Methods of test for masonry - Part 1: Determination of compressive strength.

[22] UNI EN 1052-3:2007 Methods of test for masonry Part 3: Determination of initial shear strength.

[23] M.B. Ravula, Kolluru V.L. Subramaniam, Cohesive-frictional interface fracture behaviour in soft-brick masonry: experimental investigation and theoretical development, Mater. Struct. (2019) 52:34.

[24] ASTM E519: 2007 Standard Test Method for Diagonal Tension (Shear) in Masonry Assemblages.

[25] P.B. Lourenço, J.G. Rots, Multisurface interface model for analysis of masonry structures, J. Eng. Mech. 123 (1997) 660-668.

[26] K.F. Abdulla, L.S. Cunningham, M. Gillie, Simulating masonry wall behaviour using a simplified micro-model approach, Eng. Struct. 151 (2017) 349-365.

[27] D. Gay, S.V. Hoa, S.W. Tsai, Composite materials: design and applications, CRC Press (2003)

[28] F. Lebon, S. Dumont, R. Rizzoni, J.C. López-Realpozo, R. Guinovart-Díaz, R. RodríguezRamos, J. Bravo-Castillero, F.J. Sabina, Soft and hard anisotropic interface in composite materials, Compos. Part B-Eng. 90 (2016) 58-68.

[29] https:/www.sharcnet.ca/Software/Abaqus610/Documentation/docs/v6.10/books/usb/default.ht $\mathrm{m}$ ?startat=pt06ch29s05alm45.html\#usb-elm-ecohesivebehavior

[30] P.P. Camanho, C.G. Davila, Mixed-mode decohesion finite elements for the simulation of delamination in composite materials, NASA/TM-2002-211737 (2002). 